\title{
Image Preprocessing Methods Used in Meteorological Measurement of the Temperature Testing System
}

\author{
Jiajia Zhang*, Yu Liu, He Wang \\ Meteorological Technology and Equipment Center in Hebei Province, Shijiazhuang, China \\ Email: *sunyi_12_12@sina.com
}

How to cite this paper: Zhang, J.J., Liu, Y. and Wang, H. (2016) Image Preprocessing Methods Used in Meteorological Measurement of the Temperature Testing System. Journal of Geoscience and Environment Protection, 4, 1-5.

http://dx.doi.org/10.4236/gep.2016.411001

Received: October 13, 2016

Accepted: October 27, 2016

Published: October 30, 2016

Copyright $\odot 2016$ by authors and Scientific Research Publishing Inc. This work is licensed under the Creative Commons Attribution International License (CC BY 4.0).

http://creativecommons.org/licenses/by/4.0/

\begin{abstract}
The meteorological measurement automatic temperature testing system has a defective image. To solve the problem such as noise and insufficient contrast, and put forward the research program for image pretreatment, the median filter, histogram equalization and image binarization, methods were used to remove noise and enhance images. Results showed that feature points were clear and accurate after the experiment. This simulation experiment prepared for the follow-up subsequent recognition process.
\end{abstract}

\section{Keywords}

Temperature Testing System, Thermometer Image, Image Pretreatment, Median Filter, Histogram Equalization, Image Binarization

\section{Introduction}

In order to obtain an accurate temperature effectively, we must first eliminate the effects of human factors. This is especially important in the verification process of the glass thermometer. If one can transmit the image they saw during verification to the computer to extract the information about "mercury" feature and compare it with prescribed range scales, the precise scale value will be achieved.

\section{Image Pre-Processing}

Temperature automated verification system is the most important of image processing, and image pre-processing thermometer is the first step in image processing. Owing to the different input image thermometer filming conditions, defects tend to noise, insuf- 
ficient contrast and the like. In addition, the crew distance, focal length ranging in size also makes the level of information in the entire image position and size is not identified. Therefore desirable by the temperature obtained by the image data pre-processing to eliminate the influence of illumination, focal length, and distance to a certain extent on the conditions.

\section{Image De-Noising Smoothing}

Median filter (Media filtering) is based on a sort of statistical theory can effectively suppress noise nonlinear signal processing technology [1]. The advantage of this filter is a simple and fast operation, showing filtered white noise superimposed noise and long tail terms of better performance. Details (such as edges, acute, etc.) median filtering out noise while signals can be well protected. Further, adaptive median filters easily, thereby further improving the filtering performance [2]. Therefore, it is appropriate for a number of linear filters not capable of digital image processing.

The basic idea of the median filter is: for an image, each pixel in the image as the center point produces a rectangular sliding window (window size and generally odd), all the pixels within the window at the gray value from small to large order to sort and calculate the value of the sorted sequence to the center of the window instead of pixel values.

Figure 1 is a comparison of the value after the image before and after filtering. Median overall median filter, it can effectively remove the image of a random shot noise, better to retain the original image transition section. Median filtering de-noising effect depends on the size of the filter window and participation to the number of pixels calculated.

Filtering window has on the quality of the output image is greatly affected, the window is too small to de-noising effect is not satisfactory, the window will lose too much detail, resulting in blurred images. Some fine line images and other details of the corner of the image that contains significant structural information, damage or loss of these structures are often more than the noise itself unacceptable.

Image enhancement technique is a continuation of the image contrast, image processing visual optimization techniques [3]. The main purpose of image enhancement is to increase the dynamic effects of grayscale images, highlighting some of the information in
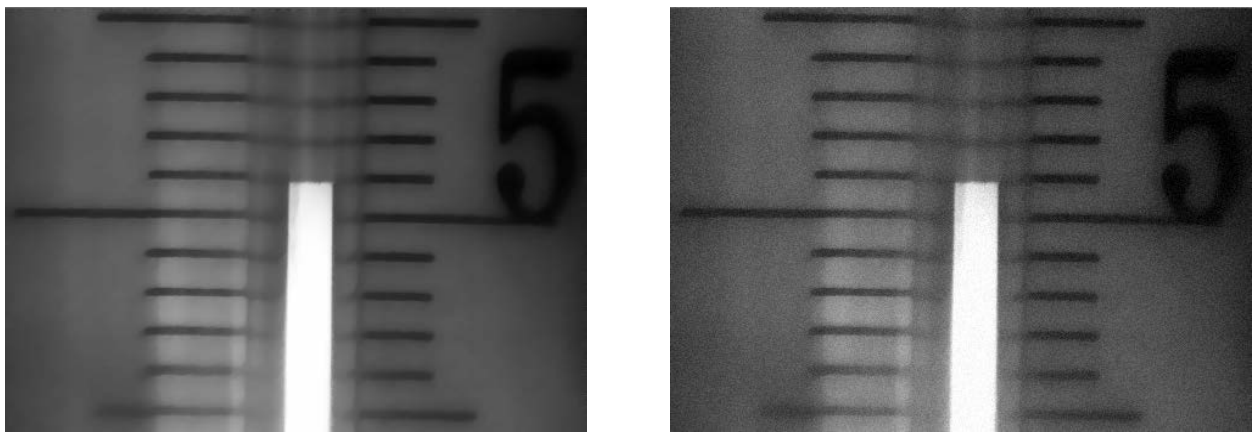

Figure 1. A comparison of the value between the image before (left) and after (right) filtering. 
the image, so that the processed image is more suitable for a particular application than the original image.

\section{Image Segmentation}

As the thermometer image we get is unevenly distributed multi-grayscale graphics, we wish to be useful image information extracted from the image thermometer out, we put this process is called image segmentation. Its purpose is tantamount to sense the image of the feature region or the need to apply the extracted feature region.

Figure 2 is a comparison of the original image and histogram thermometer standardized scale of post. Binary entropy maximization method (Abutaleb, 1989) is to develop a one-dimensional to two-dimensional gray entropy case [4]. It is the point of two-dimensional gray histogram threshold segmentation method.

The amount of information in Shannon's information theory [5] mentioned threshold is applicable to the two-dimensional image segmentation threshold. Dimensional discrete entropy is:

$$
H=-\sum_{i=1}^{L} \sum_{j=1}^{L} P_{i j} \ln P_{i j} .
$$

Single threshold value of the selected two-dimensional $(S, T)$, target and the background image is divided into two parts, denoted as $A$ and $B$. The probability of corresponding is $P_{A}$ and $P_{B}$, respectively,

$$
\begin{gathered}
P_{A}=\sum_{i=1}^{S} \sum_{j=1}^{T} P_{i j}, \\
P_{B}=\sum_{i=S+1}^{L} \sum_{j=T+1}^{L} P_{i j} .
\end{gathered}
$$

$P_{A}$ and $P_{B}$ after the implementation of normalization processing can be expressed as,

$$
\begin{cases}P_{i j}^{\prime}=P_{i j} / P_{A} & i, j \in A \\ P_{i j}^{\prime}=P_{i j} / P_{B} & i, j \in B\end{cases}
$$

Leave the two parts of the two-dimensional discrete entropy, respectively $H(A)$ and $H(B)$, the total entropy is $H$, and the maximum entropy is $H_{\max }$.
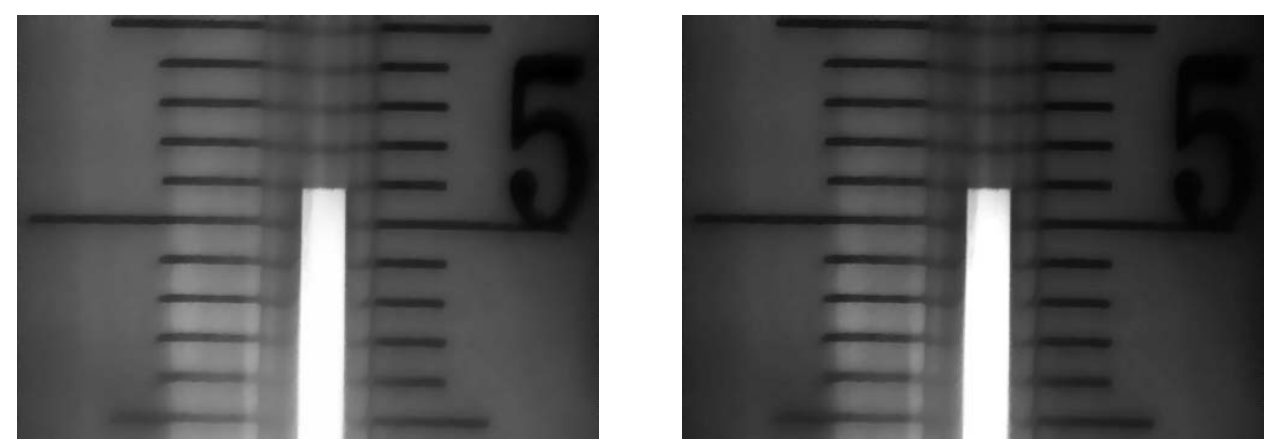

Figure 2. A comparison of the original image and histogram thermometer uniform scale of post. 

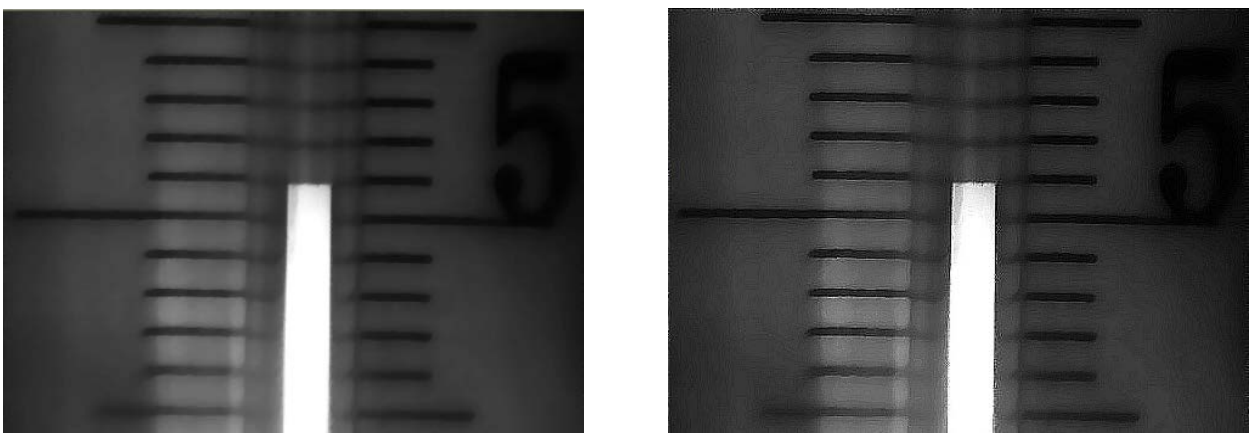

Figure 3. The image that is binarized before (left) and after (right).

$$
\begin{gathered}
H(A)=-\sum_{i=1}^{S} \sum_{j=1}^{T} P_{i j}^{\prime} \times \log \left(P_{i j}^{\prime}\right), \\
H(B)=-\sum_{i=S+1}^{L} \sum_{j=T+1}^{L} P_{i j}^{\prime} \times \log \left(P_{i j}^{\prime}\right), \\
H=H(A)+H(B), \\
H_{\max }=\arg \max (H=H(A)+H(B)),
\end{gathered}
$$

Formula is substituted into the formula obtained,

$$
H=\frac{H_{A}}{P_{A}}+\frac{H_{B}}{P_{B}}+\log _{2} P_{A}+\log _{2} P_{B},
$$

looking for an appropriate threshold $(S, T)$, so that the maximum entropy $H$ to obtain a binarized image (Figure 3 ).

\section{Conclusion}

The principal image of thermometer measurement information mentioned herein is included in the plume and the vertical and horizontal distribution of the image scale distribution. They are straight. Theoretically, we extract image feature extraction that becomes a straight line in the image in horizontal and vertical lines. However, from a severe maldistribution of gray, light and image changing images accurately extract these lines. We must choose the right way of image pre-processing, which is a necessary condition for efficient extraction of feature points.

\section{Acknowledgements}

This study was sponsored by "Temperature measurement system based on fuzzy image processing", a general project from Hebei Provincial Meteorological Bureau, China. Jiajia Zhang would like to thank Yanhua Guan, the director of Meteorological Technology and Equipment Center in Hebei Province, China for his guidance on this study.

\section{References}

[1] Rowley, H.A., Baluja, S. and Kanade, T. (1998) Neural Network-Based Face Detection. IEEE 
Transactions on Pattern Analysis and Machine Intelligence, 20, 23-28. http://dx.doi.org/10.1109/34.655647

[2] Guo, Z. and Zhang, L. (2014) Improved Adaptive Median Filter. Proceedings of the 10th International Conference on Computational Intelligence and Security (CIS), Kunming, 15-16 November 2014, 44-46.

[3] Ravi, H., Subramanyam, A.V. and Emmanuel, S. (2016) Ace-An Effective Anti-Forensic Contrast Enhancement Technique. Signal Processing Letters IEEE, 23, 212-216. http://dx.doi.org/10.1109/LSP.2015.2509477

[4] Chen, G. and Zuo, H. (2002) 2-D Maximum Entropy Method of Image Segmentation Based on Genetic Algorithm. Journal of Computer-Aided Design \& Computer Graphics, 14, 530 534.

[5] Hilbert, M. (2016) Formal Definitions of Information and Knowledge and Their Role in Growth through Structural Change. Structural Change \& Economic Dynamics, 38, 69-82. http://dx.doi.org/10.1016/j.strueco.2016.03.004

\section{Submit or recommend next manuscript to SCIRP and we will provide best service} for you:

Accepting pre-submission inquiries through Email, Facebook, LinkedIn, Twitter, etc. A wide selection of journals (inclusive of 9 subjects, more than 200 journals)

Providing 24-hour high-quality service

User-friendly online submission system

Fair and swift peer-review system

Efficient typesetting and proofreading procedure

Display of the result of downloads and visits, as well as the number of cited articles

Maximum dissemination of your research work

Submit your manuscript at: http://papersubmission.scirp.org/

Or contact gep@scirp.org 